\title{
Distâncias genéticas entre genótipos de batata a partir de dados morfológicos, moleculares e genealógicos
}

\section{Genetic distances of potato genotypes based upon using morphological, genealogical, and molecular data}

\author{
Giovani Olegário da Silva ${ }^{1 *}$; Arione da Silva Pereira ${ }^{2}$; \\ Velci Queiroz de Souza ${ }^{3}$; Caroline Marques Castro²; \\ Fernando Irajá Félix de Carvalho ${ }^{3}$; Eduardo Alano Vieira ${ }^{4}$
}

\section{Resumo}

O objetivo do trabalho foi comparar estimativas de distância genética entre genótipos de batata usando dados genealógicos, morfológicos, moleculares e conjuntamente, dados morfológicos e moleculares. Os trabalhos foram realizados na Embrapa Clima Temperado e na UFPel/FAEM/Laboratório de Genômica e Fitomelhoramento. Foi avaliado um conjunto de 13 cultivares e clones elite, componentes do Banco Ativo de Germoplasma de Batata da Embrapa Clima Temperado. Os experimentos de campo foram realizados nas primaveras de 1999, 2000, 2001, 2002 e 2003, em parcelas únicas de 20 plantas, espaçadas $0,30 \mathrm{~m}$ entre plantas e $0,80 \mathrm{~m}$ entre fileiras. Os genótipos foram avaliados em relação a 33 caracteres morfológicos de planta e tubérculo e analisados molecularmente usando marcadores AFLP. A análise de variância, considerando ano como repetição, não revelou diferenças significativas somente em relação à largura dos folíolos, frequência de flores, pigmentação do pedúnculo e aspecto do ápice. Apenas a correlação entre matrizes de dissimilaridade conjunta (morfológico e molecular) e molecular foi significativa. Portanto, todas as estimativas de distância genética entre genitores de batata deveriam ser consideradas no plano de cruzamentos.

Palavras-chave: Solanum tuberosum L, genealogia, AFLP, análise de dissimilaridade

\begin{abstract}
The objective of this work was to compare estimates of genetic distances of potato genotypes using genealogical, morphological and molecular data, and jointed data (morphological and molecular). The work was carried on at Embrapa Clima Temperado and UFPel/FAEM/Laboratório de Genômica e Fitomelhoramento. The evaluaton was with a set of 13 potato cultivars and elite clones of the Embrapa Clima Temperado Active Germoplasm Bank of Potatoes. The field experiments were grown in springs of 1999, 2000, 2001, 2002 and 2003, in single 20 plant plots, spaced at $0.30 \mathrm{~m}$ between plants and $0.80 \mathrm{~m}$ between rows. The genotypes were evaluated morphologically for 33 plant and tuber traits and for AFLP markers. The analysis of variance, considering year as replication, revealed no significant differences only for leaflet width, flowers frequency, stalk pigmentation e apex aspect. Correlations between dissimilarity matrices were significant only for jointed (morphologic and molecular) and molecular matrix. Therefore, all estimates of genetic distance between potato genitors should be considered in planning crosses.
\end{abstract}

Key words: Solanum tuberosum L, genealogy, AFLP, dissimilarity analysis

1 Embrapa Transferência de Tecnologia, C. Postal 317, 89460-000, Canoinhas-SC, E-mail: olegario@cnph.embrapa.br

2 Embrapa Clima Temperado, C. Postal 403, 93001-970, Pelotas-RS, E-mail: arione@cpact.embrapa.br, caroline@cpact.embrapa.br, velciq@gmail.com.

3 Universidade Federal de Pelotas, C. Postal 354, 96010-900, Pelotas-RS, E-mail: carvalho@ufpel.edu.br.

4 Embrapa Cerrados, C. Postal 08223, 73310-970, Planaltina-DF, E-mail: vieiraea@cpac.embrapa.br

* Autor para correspondência 


\section{Introdução}

Em batata, o desafio de identificar genótipos com características superiores é dificultado devido às diferenças que devem ser detectadas em relação às cultivares existentes atualmente serem cada vez menores, e o número de caracteres considerados no momento da seleção, cada vez maiores. Isto se deve, em grande parte, ao estreitamento da base genética da cultura (HAWKES, 1978). Portanto, o melhoramento, principalmente em longo prazo, deve ser baseado em estratégias que possibilitem maximizar a distância entre os genitores dos blocos de cruzamentos, favorecendo a complementação de alelos para aumentar a heterose.

Os estudos de distância têm sido de grande importância em programas de melhoramento, por fornecerem informações sobre parâmetros de identificação de genitores que possibilitem grande efeito heterótico e maior probabilidade de recuperar genótipos superiores nas progênies (CRUZ; REGAZZI, 1997). Tal expectativa decorre do fato que, segundo Falconer (1981), a heterose e a capacidade específica de combinação entre dois genitores, dependem da existência de dominância no controle do caráter e da presença de divergência entre os genitores.

Aanálise da distância é uma ferramenta auxiliar de grande importância em programas de melhoramento e um importante elo entre a conservação e a utilização dos recursos genéticos disponíveis. Esta estimativa possibilita a obtenção de informações a respeito da organização do germoplasma, um aumento na eficiência da amostragem de genótipos, auxílio na definição de cruzamentos artificiais, na incorporação de genes de germoplasma exótico e até na indicação de cultivares para determinada região, quando o objetivo é aumentar a base genética dos cultivares sob cultivo (MOHAMMADI; PRASANNA, 2003).

A determinação da dissimilaridade, onde diversos caracteres são avaliados simultaneamente nos genótipos, é muito vantajosa na identificação da variabilidade genética (MOURA et al., 1999).
As medidas de distância podem ser estimadas com base na avaliação morfológica do fenótipo da planta (CRUZ; REGAZZI, 1997), por meio de dados moleculares através do polimorfismo de DNA (OLIVEIRA, 1998; DINIZ FILHO, 2000), ou ainda mediante informações disponíveis da genealogia (BARBOSA-NETO; SORRELLS; CISAR, 1996; KIM; WARD, 1997; VAN BEUNINGEN; BUSEH, 1997; LOISELLE; TAI; CHRISTIE, 1991).

A herdabilidade, como indicativo de superioridade de origem genética que pode ser transmitida aos descendentes, é um bom parâmetro para a quantificação do avanço de seleção. Para o melhoramento da batata, a herdabilidade no sentido amplo é mais importante devido aos efeitos de dominância e epistasia serem mantidos pela propagação clonal. No entanto, a herdabilidade por si só não é suficiente para predizer o ganho de seleção para um caráter, dependendo também da extensão da variabilidade genética em uma população (GOPAL, 2002).

O objetivo do trabalho foi analisar a utilização de medidas de distância por meio de genealogia, caracteres morfológicos, moleculares e conjunta (morfológicos e moleculares) em batata.

\section{Material e métodos}

Os experimentos foram realizados na Embrapa Clima Temperado e no Laboratório de Genômica e Fitomelhoramento da Faculdade de Agronomia Elizeu Maciel/Universidade Federal de Pelotas. Foi avaliado um conjunto de 13 cultivares e clones elite (escolhidos ao acaso) componentes do Banco Ativo de Germoplasma da Embrapa Clima Temperado.

Os genótipos foram cultivados nas primaveras dos anos de 1999, 2000, 2001, 2002 e 2003, em campo, em parcelas de 20 plantas, sem repetições, espaçadas $0,30 \mathrm{~m}$ entre plantas e $0,80 \mathrm{~m}$ entre fileiras e manejadas com os tratos culturais recomendados para cultivo em campo. Os tubérculos foram colhidos aproximadamente 110 dias após o plantio. 
Foram avaliados 33 caracteres morfológicos nas plantas e nos tubérculos, os quais fazem parte dos descritores mínimos da batata (Solanum tuberosum L.) recomendados pelo Sistema Nacional de Proteção de Cultivares (SNPC). Os caracteres foram: formato do broto, coloração da base do broto, intensidade de coloração da base do broto, pubescência da base do broto, aspecto do ápice do broto, intensidade de primórdios radiculares do broto, comprimento da brotação lateral do broto, tipo de planta em relação à folhagem, hábito de crescimento da planta, pigmentação da haste da planta, asas da planta, inserção das folhas, fechamento das folhas, pigmentação na nervura principal das folhas, tamanho dos folíolos, largura dos folíolos, coalescência dos folíolos, ondulação das bordas dos folíolos, freqüência de folíolos secundários, freqüência de flores na inflorescência, comprimento do pedúnculo floral, pigmentação do pedúnculo floral, coloração da parte interna da corola, intensidade de pigmentação na parte interna da corola, pigmentação na parte externa da corola, freqüência de frutos, desenvolvimento, ciclo vegetativo, formato de tubérculos, profundidade de olhos, aspereza de película, cor de película e cor de polpa, avaliados segundo notas especificadas em Brasil (1997).

Os dados morfológicos foram submetidos à análise de homogeneidade de variância (teste de Bartllet) (STEEL; TORRIE, 1980) e normalidade (Lilliefors)(CAMPOS, 1983).Posteriormente, foram submetidos à análise de variância considerando ano como repetição, objetivando verificar a efetividade dos caracteres em diferenciar os genótipos e obter uma estimativa da herdabilidade a partir dos sucessivos anos de cultivo; procedeu-se ainda à análise da distância Euclidiana (ideal para dados sem repetição) para os dados fenotípicos, com utilização do programa GENES (CRUZ, 2001).

O DNA genômico utilizado na quantificação da similaridade molecular entre os 13 genótipos, com base em marcadores moleculares, foi extraído de acordo com o protocolo descrito por Saghai-
Marrof et al. (1984). Os reagentes e procedimentos requeridos para análise com AFLP foram obtidos junto a Life Techonologies Inc., na forma de Kit completo. No trabalho foram empregadas cinco combinações de iniciadores (C1: E + ACC/M + CAT; C2: E + AGC/M + CTC; C3: E + ACT/M + CAC; C4: $\mathrm{E}+\mathrm{ACT} / \mathrm{M}+\mathrm{CAG} ; \mathbf{C 5}: \mathrm{E}+\mathrm{ACT} / \mathrm{M}+$ CTT; C6: E + ACT/M + CTG; C7: E + ACT/M + CAA; C8: $\mathrm{E}+\mathrm{AGC} / \mathrm{M}+\mathrm{CTG}$, onde C: combinação de primers; E: EcoRI e M: MseI), dos quais foram obtidas 285 bandas polimórficas. Os fragmentos amplificados foram separados eletroforeticamente em gel desnaturante de poliacrilamida (6\%) a uma potência constante de $60 \mathrm{~W}$ por um período de aproximadamente 1 h e 40 '. Para a visualização dos fragmentos amplificados e separados eletroforeticamente foi empregada a coloração com nitrato de prata, de acordo com o protocolo descrito por Creste, Tulmann-Neto e Figueira (2001). As bandas geradas pela técnica de AFLP foram classificadas como presente (1) e ausente (0) para os diferentes genitores. A similaridade molecular (SM) foi estimada de acordo com Jaccard, com utilização do programa NTSYSpc (ROHLF, 2000). Subtraindo-se o valor de SM da unidade (1 - SM) foi obtida a dissimilaridade molecular.

A distância genealógica foi obtida utilizando o programa estatístico computacional SAS Learning Edition (2002) pelo procedimento PROC Imbreeding.

A matriz de distância conjunta (dados moleculares e fenotípicos) foi estimada por meio do índice de similaridade proposto por Gower (1971), posteriormente, a similaridade conjunta (SC) estimada por meio do programa Multiv v. 2.3 (PILLAR, 1997). A dissimilaridade entre os genótipos foi obtida pelo complemento do índice de Gower (1 - SC).

As matrizes de dissimilaridade foram transferidas para o programa NTSYSpc (ROHLF, 2000) para o agrupamento em dendrograma pelo método de agrupamento das distâncias médias (UPGMA) e 
diagnóstico das correlações cofenéticas entre as matrizes e os agrupamentos (ROHLF; SOKAL, 1981), bem como as correlações entre as matrizes (MANTEL, 1967).

\section{Resultados e discussão}

De acordo com a Tabela 1, ao se utilizar os caracteres largura dos folíolos (LagF), freqüência de flores (FreFl), pigmentação do pedúnculo (PigP) e aspecto do ápice (Aspecto) não é possível diferenciar os genótipos estudados, ou seja, não há diferenças significativas. Entretanto, para todos os demais caracteres analisados foram detectadas diferenças significativas, podendo estes serem eliminados das avaliações de caracterização dos genótipos. Os coeficientes de variação, que indicam a variação ocorrida na avaliação dos genótipos nos anos avaliados, variaram de 7,94 \% para tamanho de folha (TamF) até valores acima de 50\% para pigmentação do pedúnculo (53\%) e freqüência de frutos (65\%), demonstrando estes últimos serem altamente influenciados pelo ambiente nos sucessivos anos de cultivo.

Tabela 1. Resumo da análise de variância, herdabilidades e coeficientes de variação (CV) para caracteres componentes dos descritores mínimos, avaliados em 13 genótipos de batata. Pelotas, 2006.

\begin{tabular}{|c|c|c|c|c|c|c|c|c|c|c|c|c|}
\hline \multirow{2}{*}{ F.V. } & \multirow{2}{*}{ GI } & \multicolumn{11}{|c|}{ Quadrado Médio de Tratamento } \\
\hline & & Asas & Aspecto & AspPel & Ciclo & CoaFo & $\mathrm{ComBr}$ & ComP & CrBroto & CorInt & CrPel & CrPolp \\
\hline Genótipos & 12 & $0,46^{*}$ & 2,78 & $2,20 *$ & $5,11 *$ & $0,21 *$ & $4,37 *$ & $6,72 *$ & $8,02 *$ & $0,57 *$ & $0,72 *$ & $2,95^{*}$ \\
\hline CV $(\%)$ & - & 15,41 & 14,30 & 32,11 & 28,69 & 29,53 & 14,43 & 44,00 & 19,70 & 49,00 & 18,51 & 17,40 \\
\hline \multirow[t]{2}{*}{ herdabilidade } & - & 69,00 & 88,13 & 87,99 & 93,00 & 43,15 & 90,53 & 61,69 & 91,83 & 52,69 & 92,90 & 91,22 \\
\hline & & Des & Fbroto & FecF & Folhg & FFSec & FreFl & Frutos & FTub & $\mathrm{HC}$ & Inser & IntCInt \\
\hline Genótipos & 12 & $4,46^{*}$ & $1,97 *$ & $1,22 *$ & $0,70^{*}$ & $1,38^{*}$ & 0,18 & $5,38^{*}$ & $2,71 *$ & $2,78^{*}$ & $0,39^{*}$ & $18,63^{*}$ \\
\hline CV $(\%)$ & - & 13,51 & 20,63 & 10,22 & 17,00 & 10,67 & 23,47 & 65,00 & 21,23 & 14,30 & 9,36 & 12,00 \\
\hline \multirow[t]{2}{*}{ herdabilidade } & - & 92,67 & 51,20 & 77,24 & 77,00 & 75,83 & 0,01 & 65,00 & 88,64 & 88,13 & 91,88 & 93,80 \\
\hline & & IntCr & IntPrim & LagF & Olhos & OndF & PigExt & PigP & $\mathrm{PgH}$ & $\mathrm{PgN}$ & Pubsc & TamF \\
\hline Genótipos & 12 & $3,68^{*}$ & $3,22 *$ & 0,25 & $0,95^{*}$ & $2,87^{*}$ & $0,77 *$ & 0,16 & $14,95 *$ & $0,63^{*}$ & $0,21^{*}$ & $0,46^{*}$ \\
\hline CV $(\%)$ & - & 15,78 & 14,29 & 7,92 & 36,80 & 35,64 & 50,00 & 53,00 & 28,60 & 34,21 & 13,62 & 7,94 \\
\hline herdabilidade & - & 93,14 & 92,25 & 37,75 & 76,27 & 84,70 & 76,00 & 0,01 & 95,42 & 73,38 & 63,23 & 63,19 \\
\hline
\end{tabular}

*Significativo a 5\% de probabilidade de erro pelo teste F.

Asas: presença de asas, Aspecto: aspecto do ápice, AspPel: aspereza da película, Ciclo: ciclo vegetativo, CoaFo: coalescência da folha, ComBr: comprimento da brotação lateral, ComP: comprimento do pedúnculo, CorInt: coloração interna da corola, CrBroto: coloração da base do broto, CrPel: cor da película, CrPolp: cor da polpa, Des: deselvolvimento da planta, Fbroto: formato do broto, FecF: fechamento da folha, FFSec: freqüência de folíolos secundários, Folhg: tipo de folhagem, FreFl: freqüência de flores, Frutos: freqüência de frutos, FTub: formato de tubérculo, HC: hábito de crescimento, Inser: inserção da folha, IntCInt: intensidade de coloração interna da corola, IntCr: intensidade de coloração da base do broto, IntPrim: intensidade de primórdios radiculares, LagF: largura dos folíolos, Olhos: profundidade de olhos, OndF: ondulação das bordas, PgH: pigmentação da haste, PgN: pigmentação da nervura, PigExt: pigmentação externa da corola, PigP: pigmentação do pedúnculo, Pubsc: pubescência da base do broto, TamF: tamanho dos folíolos.

As estimativas de herdabilidade foram menores para os caracteres que não apresentaram significância pela análise de variância e maiores que 90\% para pigmentação da haste, inserção da folha, intensidade de coloração interna da corola, desenvolvimento da planta, ciclo vegetativo, coloração da base do broto, intensidade de primórdios radiculares, comprimento da brotação lateral, coloração da película e coloração da polpa, e valores muito próximos a 90\% para hábito de crescimento, formato de tubérculo e aspereza de película. Os elevados valores de herdabilidade para formato de tubérculo e aspereza de película concordam com as obtidas por Love, Werner e Pavek (1997). Da mesma forma, Pinto 
(1999) verificou elevado valor de herdabilidade para formato de tubérculo, demonstrando serem caracteres pouco influenciados pelo ambiente. No entanto, a herdabilidade por si só não é suficiente para predizer a resposta da seleção para um caráter, dependendo também da magnitude da variabilidade genética em uma população (GOPAL, 2001), que pode ser verificada pelas estimativas de distância.

Os dendrogramas representativos da distância entre os genótipos podem ser visualisados nas Figuras 1 e 2. Os coeficientes da correlação cofenética, que indicam quanto os dados das matrizes de dissimilaridade estão representados nos dendrogramas, foram de 0,72, 0,83, 0,72 e 0,70 para as dissimilaridades com base nos dados morfológicos, genealógicos, moleculares e conjuntos (morfológicos e moleculares), respectivamente, indicando que os dados das matrizes estão bem representados nos dendrogramas (MANTEL, 1967).

Pela análise do dendrograma obtido com base na distância Euclidiana, a partir dos dados morfológicos, pode-se observar pela distância média entre os genótipos $(8,30)$, que há um grupo maior composto de 9 dos 13 genótipos avaliados, um agrupamento menor composto pelos genótipos Asterix e Baronesa e ainda White Lady e C-17147-94 que não agruparam com nenhum genótipo, indicando que a maioria dos genótipos possui similaridade muito grande e que para maximizar a heterose os componentes do grupo maior não poderiam ser cruzados entre si (LUTHRA; GOPAL; SHARNA, 2005) (Figura 1A).

A dissimilaridade média entre os genótipos com base na genealogia foi de 0,99 , demonstrando que dos 13 genótipos avaliados seis ficaram isolados. Este fato ocorreu provavelmente devido a não existência de relação genealógica entre estes ou devido a não haver completa informação de descendência dos mesmos. Os demais 7 genótipos foram agrupados em um grande grupo (Figura 1B).
A dissimilaridade média entre os genótipos por marcadores moleculares foi de 0,78. Três agrupamentos de genótipos foram formados, um maior grupo composto de oito genótipos e dois agrupamentos menores, um formado por Baronesa e Atlantic e outro por Monalisa, C-1485-16-87 e C-1226-35-80 (Figura 2A).

Com base na análise conjunta dos dados morfológicos e moleculares, foi observado a dissimilaridade média entre os genótipos de 0,32. Com base na dissimilaridade média, é identificada a formação de um grande grupo, composto por 7 genótipos e ainda dois agrupamentos de 2 genótipos, um formado por White Lady e C-1714-7-94 e outro por Baronesa e Elvira, havendo 2 genótipos que não agruparam com nenhum outro (Figura 2B).

De maneira geral, fazendo as comparações dos quatro dendrogramas que estão apresentados nas Figuras 1 e 2, verifica-se que em algumas situações os genótipos não foram agrupados da mesma forma em todas as situações. A comparação entre as quatro matrizes de distância foi realizada mediante a correlação entre matrizes (MANTEL, 1967). Os valores de correlação entre as matrizes foram os seguintes: conjunta com fenotípica 0,09 , conjunta com genealógica 0,18 , conjunta com molecular 0,55 , fenotípica com genealógica 0,16 , fenotípica com molecular 0,20 e genealógica com molecular 0,04. Apenas a correlação entre a matriz de distância conjunta com a matriz molecular foi significativa pelo teste de Mantel (1967).

Esta associação significativa pode ter ocorrido devido a grande quantidade de marcadores moleculares em relação aos caracteres morfológicos na análise conjunta, assim os resultados podem ter sido superestimados na associação devido ao número de marcadores moleculares (FRANCO et al., 2001). A ausência de associações com a dissimilaridade genealógica provavelmente foi devido ao reduzido volume de informações sobre a genealogia dos genótipos, conforme citado anteriormente. 

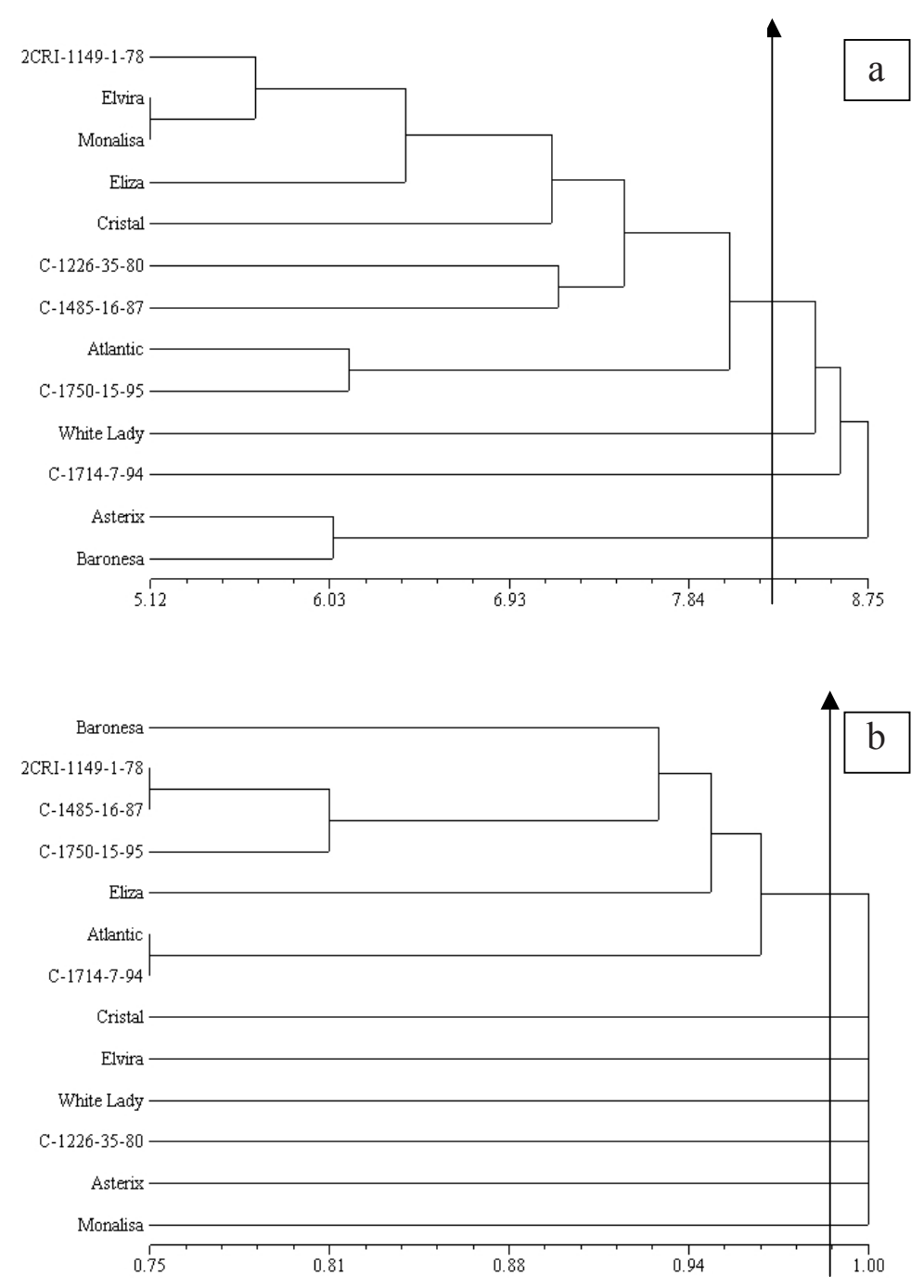

Figura 1. Dendrogramas de distância entre 13 genitores de batata, com base em dados morfológicos (A) e genealógicos (B), agrupados pelo método de agrupamento UPGMA, Pelotas, 2006.

${ }^{1}$ Distância média entre os genótipos.

Quanto à associação entre marcadores moleculares e morfológicos, a primeira propicia uma amostragem muito mais ampla do genoma do que a análise com caracteres morfológicos, portanto os dois marcadores possibilitariam avaliar partes diferentes do genoma. A associação fica também dificultada pelo diferente número de marcadores morfológicos e moleculares utilizados (LEFEBVRE et al., 2001; MÁRIC et al., 2004; ROY et al., 2004).
Devido ao fato de os parâmetros de medida utilizados para a estimação das distâncias não se correlacionarem, eles podem ser considerados em conjunto para maximizar o nível de variação presente na população obtida pelo cruzamento de genótipos com maiores distâncias, sendo, portanto, informações complementares. Dessa forma, a combinação de diferentes medidas pode melhorar a predição da performance da progênie, variabilidade ou ambas (AUTRIQUE et al., 1996; BERED et al., 2001). 

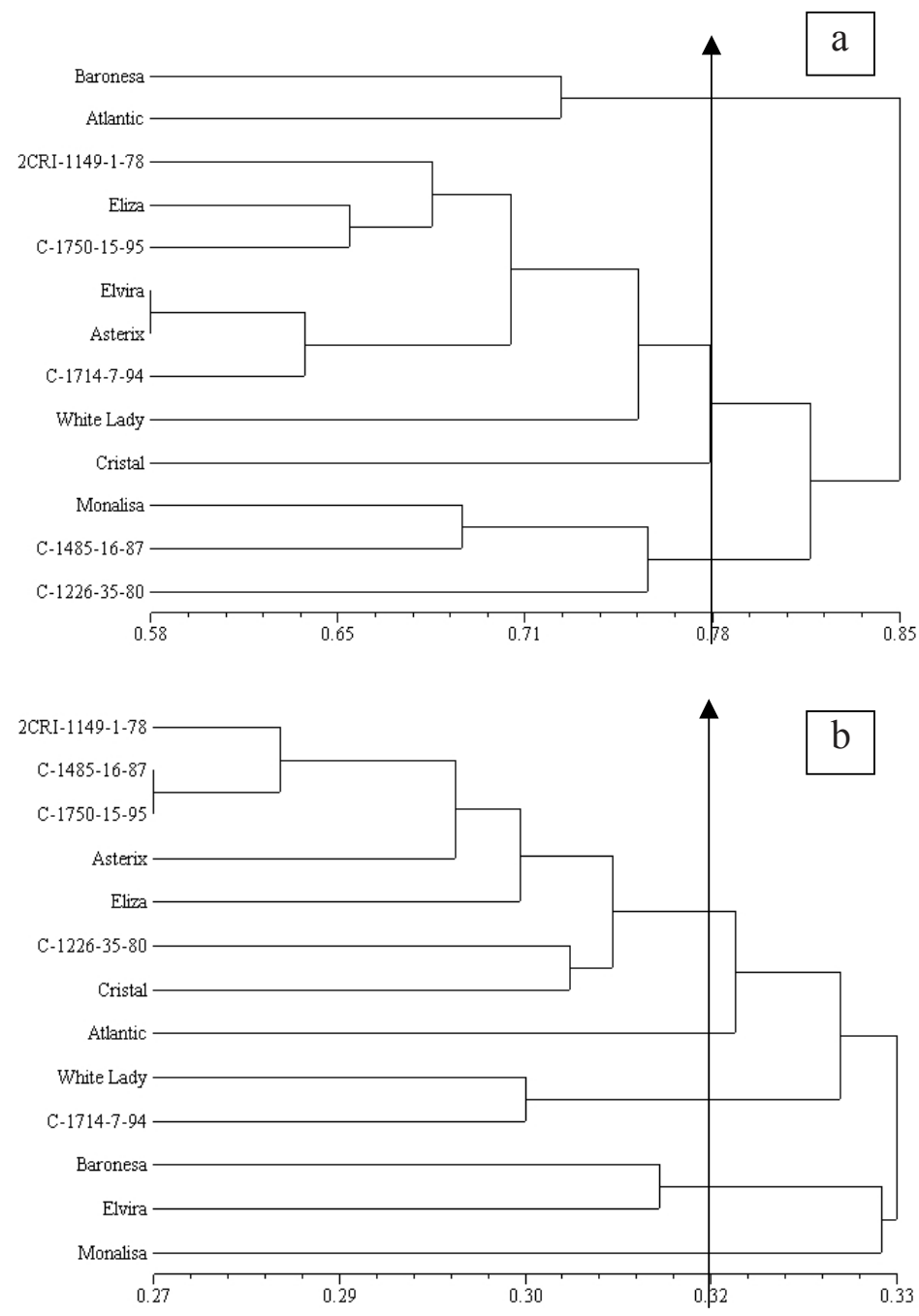

Figura 2. Dendrogramas de distância entre 13 genitores de batata, com base em dados moleculares (A) e conjunta (moleculares e morfológicos) (B), agrupados pelo método UPGMA, Pelotas, 2006.

${ }^{1}$ Distância média entre os genótipos.

\section{Referências}

AUTRIQUE, E.; NACHIT. M. M.; MONNEVEUX, P.; TANKSLEY, S. D.; SORRELS, M. E. Genetic diversity in Durum wheat base don RFLPs, morphophysiological traits, and coefficient of parentage. Crop Science, Madison, v. 36, p. 735-742, 1996.

BARBOSA-NETO, J. F.; SORRELLS, M. E.; CISAR, G. Prediction of heterosis in wheat using coefficient of parentage and RFLP based estimates of genetic relationship. Genome, Montreal, v. 39, n. 6, p. 11421149, 1996.

BERED, F.; BARBOSA-NETO, J. F.; ROCHA, B. M.; CARVALHO, F. I. F. Genetic variability in common wheat base don morphological traits, coefficients of parentage and RAPDs. Journal of New Seeds, New York, v. 3, n. 2, p. 73-85, 2001.

BRASIL. Decreto no 2.366, de 5 de novembro de 1997. Regulamenta a proteção de cultivares e os descritores das primeiras oito espécies que serão protegidas: algodão, arroz, batata, feijão, milho, soja, sorgo e trigo. Biotecnologia Ciência \& Desenvolvimento, Brasília, v. 1, n. 3, p. 23-32, 1997.

CAMPOS, H. Estadística experimental não-paramétrica. 4. ed. Piracicaba: FEALQ, 1983. 349 p.

CRESTE, S.; TULMANN-NETO, A.; FIGUEIRA, A. Detection of single sequence repeat polymorphism in 
denaturing polyacrylamide sequencing gels by silver staining. Plant Molecular Biology Reporter, Athens, v. 19, n. 4, p. 1-8, 2001.

CRUZ, C. D. Programa Genes: Aplicativo computacional em genética e estatística. Viçosa: UFV, 2001.

CRUZ, C. D.; REGAZZI, A. J. Divergência genética. In: CRUZ, C. D.; REGAZZI, A. J. Métodos biométricos aplicados ao melhoramento genético. Viçosa: UFV, 1997. p. 287-324. 6 v.

DINIZ FILHO, J. A. Métodos filogenéticos comparativos. Ribeirão Preto: Holos, 2000.

FALCONER, D. S. Introdução à genética quantitativa. Viçosa: UFV, 1981.

FRANCO, J.; CROSSA, J.; RIBAUT, J. M.; BETRAN, M. L.; WANBURTON, M. L.; KHAIRALLAH, A. A method for combining molecular markers and phenotypic attributes for classifying plant genotypes. Theoretical and Applied Genetics, New York, v. 103, n. 6, p. 944952, 2001.

GOPAL, J. Genetic parameters and character associations for family selection in potato breeding programmes. Journal of Genetics \& Breeding, Roma, v. 55, n. 3, p. 201-208, 2001.

GOPAL, J. Genetic parameters and character associations for family selection in potato breeding programmes. Journal of Genetics \& Breeding, Roma, v. 55, n. 5, p. 201-208, 2002.

GOWER, J. C. A general coefficient of similarity and some of its properties. Biometrics, Washington, v. 27, n. 4, p. 857-874, 1971.

HAWKES, J. G. History of the potato. In: HARRIS, P. M. The potato crop: The scientific basis for improvement. London: Chapman \& Hall, 1978. p. 1-14.

KIM, H. S.; WARD, R. W. Genetic diversity in Eastem U.S. soft winter wheat (Triticum aestivum L. em. Thell.) based on RFLPs and coefficient of parentage. Theoretical and Applied Genetics, New York, v. 94, n. 3/4, p. 472479, 1997.

LEFEBVRE, V.; GOFFINET, B.; CHAUVET, J. C.; CAROMEL, B.; SIGNORET, P.; BRAND, R.; PALLOIX, A. Evaluation of genetic distances between pepper inbred lines for cultivar protection purposes: comparison of AFLP, RAPD, and phenotypic data. Theoretical and Applied Genetics, New York, v. 102, n. 5, p. 741-750, 2001.

LOISELLE, F.; TAI, G. C. C.; CHRISTIE, B. R. Pedigree, agronomic and molecular divergence of parents in relation to progeny performance in potato. Potato Research, Wageningen, v. 34, n. 3, p. 305-316, 1991.
LOVE, S. L.; WERNER, B. K.; PAVEK, J. J. Selection for individual traits in the early generations of a potato breeding program dedicated to producing cultivars with tubers having long shape and russet skin. American Potato Journal, Orono, v. 74, n. 3, p. 199-213, 1997.

LUTHRA, S. K.; GOPAL, J.; SHARNA, P. C. Genetic divergence and its relationship with heterosis in potato. Indian Potato Journal, New Delhi, v. 32, n. 1/2, p. 37-42, 2005.

MANTEL, N. The detection of disease clustering and a generalized regression approach. Cancer Research, Chestnut, v. 27, n. 2, p. 209-220, 1967.

MÁRIC, S.; BOLARÍC, S.; MARTINCIC, I.; PEJIC, I.; KOZUMPLIK, V. Genetic diversity of hexaploid wheat cultivars estimated by RAPD markers, morphological traits and coefficients of parentage. Plant Breeding, Berlin, v. 123, n. 4, p. 366-369, 2004.

MOHAMMADI, S. A.; PRASANNA, B. M. Analyses of genetic diversity in crop plants - Salient statistics tools and considerations. Crop Science, Madisson, v. 43, n. 4, p. 1235-1248, 2003.

MOURA, W. M.; CASALI, V. W. D.; CRUZ, C. D.; LIMA, P. C. Divergência genética em linhagens de pimentão em relação à eficiência nutricional de fósforo. Pesquisa Agropecuária Brasileira, Brasília, v. 34, n. 2, p. 217-224, 1999.

OLIVEIRA, A. C. Construção de Mapas Genéticos em Plantas. In: MILACH, S. C. K. (Ed.) Marcadores de DNA em Plantas. Porto Alegre: UFRGS, 1998.

PILLAR, V. P. Multivariate exploratory analysis and randomization testing using Multiv. Coenoses, Gorizias, v. 12, p. 145-148, 1997.

PINTO, C. A. B. Melhoramento genético de batata. Informe Agropecuário UFLA. Belo Horizonte, v. 20, n. 197, p. 120-128, 1999.

ROHLF, F. J. NTSYSpc numerical taxonomy and multivariate analysis system version 2.1. New York: Exeter Software, 2000.

ROHLF, F. J.; SOKAL, R. R. N. Comparing numerical taxonomic studies. Systematic Zoology, Washington, v. 30, n. 4, p. 459-499, 1981.

ROY, J. K.; LAKSHMIKUMARAN, M. S.; BALYAN, H. S.; GUPTA, P. K. AFLP-based genetic diversity and its comparison with diversity based on SSR, SAMPL, and phenotypic traits in bread wheat. Biochemical Genetics, New York, v. 42, n. 1/2, p. 43-59, 2004.

SAGHAI-MAROOF, M. A.; SOLIMAN, K. M.; JORGENSEN, R. A.; ALLARD, R. W. Ribosomal DNA spacer length polymorphism in barley: Mendelian 
inheritance, chromosome location and population dynamics. Proceedings of the National Academy of Sciences of the U.S.A, Washington, v. 89, n. 2, p. 14771481, 1984.

SAS LEARNING EDITION. Getting Started with the SAS Learning Edition. Care: SAS Institute Inc, 2002.
STEEL, R. G. D.; TORRIE, J. H. Principles and procedures of statistics. 2. ed. New York: McGraw-Hill Book, 1980.

VAN BEUNINGEN, L. T.; BUSEH, R. H. Genetic diversity among North American spring wheat cultivars: I. Analysis of the coefficient of parentage matrix. Crop Science, Madisson, v. 37, p. 570-579, 1997. 
